
\title{
is Research Square \\ COVID-19 pandemic fear and anxiety among healthcare professionals in Pakistan
}

\section{Zohra Saleem}

Dow University of Health Sciences, Karachi,Pakistan.

Muhammad Mansoor Majeed ( $\sim$ mmansoormajeed@gmail.com )

Altamash Institute of Dental Medicine, Karachi,Pakistan. https://orcid.org/0000-0002-4237-6116

\section{Sara Rafique}

Jinnah Medical and Dental College, Karachi,Pakistan.

\section{Zarah Siqqiqui}

Dow University of Health Sciences, Karachi,Pakistan.

\section{Dinaz Ghandhi}

Altamash Institute of Dental Medicine, Karachi,Pakistan.

\section{Hira Tariq}

Federal Post Graduate Medical Institute, Shaikh Zayed Hospital, Lahore, Pakistan.

Jonathan Adrián Zegarra-Valdivia

Universidad Nacional de San Agustín de Arequipa - Peru

\section{Research Article}

Keywords: Healthcare Professionals, COVID-19, Fear, Anxiety, Pakistan

Posted Date: July 23rd, 2020

DOI: https://doi.org/10.21203/rs.3.rs-37608/v2

License: (a) (i) This work is licensed under a Creative Commons Attribution 4.0 International License. Read Full License 


\section{Abstract}

During the current pandemic, Pakistan is badly affected. It has exerted great pressure on vigor as well as the psychology of the healthcare professionals. Limited resources, illiteracy, myths, and not following the proper protocol by the general population may have increased the risk for everyone, and anxiety and fear among the frontline healthcare professionals. Anxiety is a common response to any stressful situation and its the fear of the unknown and it may have multiple consequences.

In the current study, we attempted to analyze the fear and anxiety among the healthcare professionals of Pakistan.

An online questionnaire-based survey was performed using a non-probability snowball sampling technique. The questionnaire was validated and comprised of demographics and 10 questions regarding fear and anxiety as per fear of coronavirus-19 scale (FCV-19S). SPSS 21 was used for data analysis.

Data of 404 participants analyzed. A significant difference between gender, age group, and the profession was found $(p<0.05)$. Out of 404 participants, $322(79.70 \%)$ were considered to have high and severe anxiety $(p=0.020)$. Based on the results anxiety was reported higher among the nurses and in females. A significant relationship was observed between fear and anxiety score and the different healthcare professionals with $p$ value 0.001 (Multilinear regression).

Concerning the high occurrence of anxiety and fear among healthcare professionals appropriate psychological/psychiatric intervention necessitates and emphasizes the need to implement urgent measures.

\section{Introduction}

Coronavirus disease 19 (COVID-19) is a pathogenic viral infection that presents as a new public health crisis globally $(1,2)$. It is highly transmissible and caused by severe acute respiratory syndrome coronavirus 2 (SARS- CoV-2) (1). It is thought to initially emerge in Wuhan, Hubei province, China(1). The initial cases of pneumonia of unknown cause were reported on 31st December 2019 to the World health organization (WHO) country office in China (3). Later in mid-January, officials confirmed the first case of COVID-19 outside of China in Thailand (3). Currently (mid of June), 213 countries have been affected with $7.76 \mathrm{M}$ confirmed cases of COVID-19 and around 430k deaths (3).

In response to this threatening circumstance, certain public policies were introduced by governments globally (4). These measures include self-quarantine, isolation, and social distancing (5). The implementation of these policies caused the closure of educational institutes, offices, workplaces, public places, and social gathering restrictions. People are advised to stay at home and follow advice proposed by the WHO to protect oneself and others from the spread of COVID- 19. The strict lock self-quarantine order (lockdown) has kept the entire population in isolation which has put a significant impact on people's life(6).

Uneventful circumstances such as disease outbreaks and pandemics commence fear among many individuals. People fear getting infected and then transmitting to their loved ones and other people around 
them. A study indicates that such fear has caused individuals to commit suicide because they assume that they have been infected by COVID-19 even though the autopsies showed opposite results. $(7,8)$

The variations in work routine and isolation have led to feelings of abandonment and helplessness globally. It has also caused heightened insecurity among people due to the declining economic and social repercussions of this pandemic(9). Subsequently, people are

concerned about their jobs since the process of firing and unemployment has been initiated in quite a few parts globally.

There's a constant update about the disease available on news channels and over the Internet which highlights the number of individuals affected and deaths due to COVID-19. Also, inadequate knowledge and overwhelming news may contribute to fear and anxiety among the public(10-12). People at large may experience disappointment, irritability, and boredom under isolation measures(13). The communication technologies' facilities and transmission of inaccurate or sensational information may contribute to an increase in unacceptable social reactions such as aggression and rage (14).

Suspected and confirmed COVID-19 cases are likely to experience anxiety, loneliness, depression, denial, insomnia, and fear. Suspected isolated patients may encounter anxiety due to vagueness about their health status and progressively develop obsessive-compulsive symptoms, such as sterilization and repetitive temperature evaluation (10). Furthermore, strict quarantine policy and mandatory contact tracing policy by health authorities may lead to social rejection, discrimination, financial loss, and stigmatization $(11,13)$. New psychiatric symptoms in people without mental illness can occur or aggravate the condition of those with pre-existing mental illness and cause distress to the caregivers of affected individuals (15).

Healthcare professionals are the most vulnerable group of individuals. Not just because of their direct interaction with the patient's, but HCP are in a state of anxiety due to the number of HCPs that are severely infected and (16)

Most health professionals working in isolation units and hospitals very often do not receive any training for providing mental health care (17). the confinement "caused a sense of collective hysteria, leading the staff to desperate measures" (18). Being isolated, working in high-risk positions, and having contact with infected people are common causes of trauma. (19),

Various studies have been carried out worldwide that demonstrate the psychological impact of the disease on individuals. Patients whose mental health is affected during the pandemic appears to be higher than the patients affected by the COVID-19 disease. (9)

A recent study in Canada reports one-third of the participants who were worried about the current pandemic(20). Another German study demonstrates a higher number of patients worried about COVID-19 (21). USA study based on online poll reports $56 \%$ of participants who were concerned about the transmission of COVID-19(22). In another comparative study being conducted in the USA reports that participants were more concerned about COVID-19 as compared to seasonal influenza(20, 23). In Latin 
America One of the greatest fear among the evaluated population is being in contact with healthcare professionals (24).

Health care professionals interacting with infected and non-infected patients are of no exception. They are on duty of care to the patients, interaction with the patient's relatives, and occasionally, facing the public inquiry. Studies report excessive workload, isolation, and discrimination among frontline health professionals, thus, contributing to physical exhaustion, insomnia, emotional disturbance, and fear(25). A recent study demonstrates that more than $50 \%$ of health professionals report symptoms of depression, insomnia, and anxiety(26). In Pakistan few other studies have been carried out to evaluate the knowledge, anxiety, and fear among medical doctors, dentists, and nurses (27-31).

This study aims to analyze the COVID- 19 pandemics fear among the health care professionals of Pakistan who are putting their lives on the line to serve the public as per WHO criteria that include medical doctors, dentists, nurses, and pharmacists(32).

\section{Methodology}

This is a cross-sectional observational study. A total of 404 Individuals contributed to the study. As per the classification, medical doctors, dentists, nursing professionals, and pharmacists were included in this study. Data was collected by a convenience snowball sampling technique from HCPs working in different healthcare setups in different cities of Pakistan. Participation was entirely voluntary. Informed Consent was obtained electronically from each participant and was requested to fill out the online survey form.

The questionnaire was validated by 7 experts from medicine, dentistry, nursing, and psychiatry and pretested on $20 \mathrm{HCPs}$ with experience ranges from 2- 38 years. It comprises two parts, the first consisting of demographic data including age, gender, country, and city of residence and profession and the second part comprises a total of 10 questions. It consists of a few questions obtained from fear of coronavirus- 19 scale (FCV-19S) which was developed and validated using two types of psychometric scale; classical test theory (CTT) analysis and Rasch analysis (33). The level of agreement for each question is indicated by using a five-item Likert- type scale. Answers included strongly disagree, disagree, neutral, agree, and strongly agree. For each question, the minimum score possible is 1 , and 5 is the maximum. A total score is calculated by summing up the score of all questions (ranging from 10 to 50). The higher the score, the greater the fear of the Coronavirus. We categorized anxiety levels into 5 categories

i.e. No Anxiety, Mild Anxiety, Moderate Anxiety, High Anxiety, and Severe Anxiety as per cutoff values (34).

Informed consent was obtained from each participant as per Helsinki declaration and the study protocol was approved by the ethics and review committee of Altamash Institute of Dental Medicine, Karachi, Pakistan (AIDM/EC/04/2020/04).

Data from Google form was first downloaded in Microsoft Excel and later entered in SPSS v.22 for statistical analysis. Sociodemographic data of each participant was recorded and 
reported as percentages. Internal consistency (reliability) of the questionnaire was tested by applying Cronbach's alpha an item test correlation. A Chi-square test and Multi-linear regression analysis tests were applied. P-value $<0.05$ was considered significant.

\section{Results}

Regarding the reliability, we found that our questioner has a Cronbach`s alpha of 0.82 with a $95 \%$ confidence interval between $0.798-0.849$, which is acceptable (35). We also check for item-test correlation, performed to assess the homogeneity of the test, and determine its criterion validity. Correlations vary between 0.500 (item 7) and 0.729 (item 8), which means it has moderate and significant relations between the items and the test. Considering this, no item was removed from the analysis (Table 1).

Data of $437 \mathrm{HCPs}$ was collected after filtration a total of $404 \mathrm{HCPs}$ data has been analyzed. A significant difference has been observed among males and females, 141 (34.9\%) participants were male and 263 $(65.1 \%)$ were female. In the current study, $166(41.3 \%)$ were dentists, $124(30.7 \%)$ were medical doctors, $77(18.8 \%)$ were nurses and $37(9.2 \%)$ were pharmacists. We observed that $14(3.46 \%)$ of participants were infected with COVID-19 and $34.9 \%$ of participants reported that they knew someone in their family infected with COVID-19.

Severe anxiety was reported by the majority of the health care professionals $(62.6 \%)$ whereas only $0.2 \%$ reported no anxiety. Chi-square test was applied to test the association between gender and age group, gender profession. A statically significant association was observed between gender and age group, gender, and profession (Table 2).

Chi-square was applied to test the association between questionnaire responses and the different healthcare professions. A significant association was reported between the two variables with a p-value < 0.005 for 5 questions (Items) (Table 3). We found that nurses are more anxious as compared to other health care professionals.

We found that nurses are more anxious as compared to other health care professionals. The mean Anxiety score among the nurses was recorded at $4.05 \pm 0.66$. Dentists, Medical doctors, and pharmacists scores were $3.98 \pm 0.61,3.8468 \pm 0.76,3.78 \pm 0.67$ respectively (Fig1).

The relationship between sociodemographic variables and fear and anxiety score was tested by multi-linear regression analysis. Highly significant relationship $(p<0.05)$ was found between profession and anxiety scores (Table 3).

Figure 2 demonstrates the contrast of anxiety/ fear score by sociodemographic characteristics. According to this, females overall demonstrate more anxiety in comparison to males. Among health care professionals, nurses report more anxiety levels.

\section{Discussion}


In the current study, we aimed to evaluate the fear and anxiety among the frontline warriors of Pakistan. For the current study medical doctors, dentists, nurses, and pharmacists working in different health care setup were the Participants.

We analyzed that more than $95 \%$ of the HCPs of Pakistan are under the category of moderate level of anxiety to a severe level of anxiety. A study recently conducted in Pakistan has demonstrated similar findings (29).

As per the findings of the current study, among Pakistan's healthcare professionals, nurses reported the highest anxiety and fear. Nurses have intense workload due to comprehensive monitoring, prompt recognition, and prevention of several complications, close contact with physicians, symptomatic and psychological support (36). In another study performed exclusively on nurses managing the COVID-19 patients in Karachi, Pakistan exhibits similar results(28). According to the results of this study, females have more anxiety as compare to males which are in agreement with the outcome of other studies $(37,38)$. Moreover, the results of different studies performed in Pakistan to analyze the anxiety levels of HCPs are in accordance with the finding of the current study $(27,39)$. On the other hand, we have also noticed that the level of anxiety among the pharmacist is less as compared to medical doctors, dentists, and nurses. In Pakistan the interaction of pharmacists with the patients is limited so in our opinion, this could be the reason.

In contrast to the previous studies conducted in Pakistan on HCP, in the current study we have a sufficient number of dentists. Fear and anxiety among the dentist are nearly close to the nurses' Dentists are categorized in the High-risk zone due to aerosol-generating procedures and close contacts with the patients' (40). During the current pandemic, most of the dentists have temporarily suspended the non-essential dental procedures and many dental clinics have been

temporarily shut down. Few dentists started working from home and provided free telemedicine/consultancy (41).

What is noteworthy that in the current study, we have also observed that instead of losing their life healthcare professionals of Pakistan are more concerned about transmitting the disease to the society or their family members. This shows the dedication of the frontline warriors of Pakistan even though during the last few weeks about 17 healthcare professionals in Pakistan have lost their lives and about 2000 are infected and many of them are in a constant battle between life and death (42). Furthermore, during the current crisis, thousands of HCPs and healthcare workers are infected or died in China, Spain, Italy, France, Turkey, and other parts of the world $(16,43,44)$.

A significant majority of the HCPs have a high prevalence of high to severe anxiety. Similars finding from the neighboring countries China, Iran, India further confirms our findings (45-48). Furthermore, previously a study regarding the SARS outbreak also revealed that more than $50 \%$ of the healthcare workers experienced anxiety(49). 
Moreover, in the current study, more than $90 \%$ of the HCPs are not satisfied with the facilities of health care in Pakistan and a previous study about the health care system of Pakistan further supports the current finding (50). This factor may not only increase the fear but also affects the efficacy of the HCP. And this dilemma may lead to the deterioration of HCPs' health and previous studies have emphasized that additional supplies and beds will not prove to be useful unless there's sufficient workforce $(16,51,52)$.

More than 3/4th HCP have fear of getting infected during the management of COVID-19 patients. Pakistan is a developing country with limited healthcare facilities, hence there's an immense burden on the health care system during the current pandemic. Healthcare professionals being frontline workers are at a higher risk of disease transmission. They experience a higher chance of exposure risk and face extreme workloads, moral dilemmas, and

rapidly varying working environments but at the same time, they handle societal shifts and emotional stress experienced by patients(51).

Health care professionals experience a higher chance of exposure risk and face extreme workloads, moral dilemmas, and rapidly varying working environments but at the same time, they handle societal shifts and emotional stress experienced by patients (52-55). They are at risk of lower immunity due to long working hours (36). Past studies reported extraordinary stress among health care providers during the SARS and MERS epidemic due to high infection risk, understaffing, stigmatization and uncertainty, and comprehensive support of highlighted during and after the outbreak $(56,57)$. Speedy spread and severity of symptoms of COVID-19 have acutely burdened the health care system globally. Despite the fear of getting infected, health care professionals still took up their charge, focused on their duties, and showed a spirit of dedication and unity during the current pandemic (36).

The results of our study substantiate with a recent study carried out in the United States of America, pointed out 8 sources of anxiety among health care professionals. These include, (a) access to suitable personal protective equipment, (b) disease exposure at workplace and carrying it to home, (c) non-rapid access to investigation in case of disease symptoms and the concomitant fear of transmission at work, (d) uncertainty that they would get support from their organization for their personal and family needs if they get infected, (e) child care access during increased working period and closure of educational institutes, $(f)$ personal and family support due to increase in work duration and demands including food, transportation, hydration, and lodging, $(\mathrm{g})$ being able to provide efficient medical care if posted to a new department, $(\mathrm{h})$ lack to access to advanced information and communication(51).

In agreement with the finding of the current study, a recent study demonstrates that in Pakistan, medical workers have been under pressure, both psychological and physical along with high infection risk, isolation, insufficient safety equipment, exhaustion, and lack of interaction with

the family. Mental health-related problems are appearing which affects decision making power of the health care professionals and may have a chronic negative impact on overall well- being(58). Therefore, speaking about mental health concerns is important for the prevention and control of the current pandemic (59).To improve mental health among health care professionals, it is important to focus on self-care and reduce 
overwork by setting maximal duty hours and arranging shifts (53). In addition to this, knowledge of infection, control, and protection of personnel skills should be improved among health care providers. Previous studies have shown that the knowledge among the HCPs of Pakistan is satisfactory $(31,60)$. Hospitals should play a role in providing a safe working atmosphere along with the provision of sufficient protective supplies (36). Concern about disease transmission to loved ones should be addressed.

Supportive measures such as separating living rooms, immediately showering, and changing clothing after work should be practiced by health care providers to reduce anxiety (53).

\section{Conclusion}

Our study concludes that there's a high level of anxiety and fear among health care professionals in Pakistan during the current pandemic. Considering stable mental health is essential and plays a significant role in strengthening immunity, certain measures need to be taken to reduce the fear and anxiety level among health care providers.

\section{Declarations}

\section{Conflict of Interest:-}

The authors declare that they do not have any interests that could constitute a real, potential or an apparent conflict of interest concerning their involvement in the publication

\section{Funding: None}

Acknowledgments: We acknowledge the support of the ethic and review committee of Altamash Institute of Dental Medicine, Karachi, Pakistan. We would like to extend heartfelt graciousness to Dr. Majeed Anwar, Dr. Munir and Dr. Shoaib Durrani from Karachi, Dr.Habib- ur-Rehman from Lahore, Dr. Maqsood Anwar from Islamabad, Dr. Adnan Khan from Peshawar and Dr.Fazal from Quetta,Pakistan and to all the respected HCPs who participated and provided support at every step of the research.

\section{Author's contribution: -}

SZ and MM conceived the study and designed the questionnaire. TH, ZS, and RS collected data. SZ and TH performed statistical analyses and prepared tables and figures. MM, SZ and GD drafted and revised the manuscript. MM supervised the project and is responsible for the integrity of the research. All authors contributed comprehensively contributed to writing and critically revised and approved the final draft of the manuscript.

\section{References}

1. Shereen MA, Khan S, Kazmi A, Bashir N, Siddique R. COVID-19 infection: origin, transmission, and characteristics of human coronaviruses. Journal of Advanced Research. 2020. 
2. Singhal T. A review of coronavirus disease-2019 (COVID-19). The Indian Journal of Pediatrics. 2020:1-6.

3. Organization WH. Coronavirus disease 2019 (COVID-19): situation report, 72.

4. Ahorsu DK, Lin C-Y, Imani V, Saffari M, Griffiths MD, Pakpour AH. The fear of COVID-19 scale: development and initial validation. International Journal of Mental Health and Addiction.

5. Anderson RM, Heesterbeek H, Klinkenberg D, Hollingsworth TD. How will country- based mitigation measures influence the course of the COVID-19 epidemic? The Lancet. 2020;395(10228):931-4.

6. Qiu J, Shen B, Zhao M, Wang Z, Xie B, Xu Y. A nationwide survey of psychological distress among Chinese people in the COVID-19 epidemic: implications and policy recommendations. General psychiatry. 2020;33(2).

7. Goyal K, Chauhan P, Chhikara K, Gupta P, Singh MP. Fear of COVID 2019: First suicidal case in India! Asian journal of psychiatry. 2020;49:101989.

8. Mamun MA, Griffiths MD. First COVID-19 suicide case in Bangladesh due to fear of COVID-19 and xenophobia: Possible suicide prevention strategies. Asian journal of psychiatry. 2020;51:102073.

9. Ornell F, Schuch JB, Sordi AO, Kessler "Pandemic fear" and COVID-19: mental health burden and strategies. Brazilian Journal of Psychiatry. 2020;42(3):232-5.

10. Li W, Yang Y, Liu Z-H, Zhao Y-J, Zhang Q, Zhang L, et al. Progression of mental health services during the COVID-19 outbreak in China. International journal of biological sciences. 2020;16(10):1732.

11. Shigemura J, Ursano RJ, Morganstein JC, Kurosawa M, Benedek DM. Public responses to the novel 2019 coronavirus (2019-nCoV) in Japan: mental health consequences and target populations. Psychiatry and clinical neurosciences. 2020;74(4):281.

12. Bao Y, Sun Y, Meng S, Shi J, Lu 2019-nCoV epidemic: address mental health care to empower society. The Lancet. 2020;395(10224):e37-e8.

13. Brooks SK, Webster RK, Smith LE, Woodland L, Wessely S, Greenberg N, et al. The psychological impact of quarantine and how to reduce it: rapid review of the evidence. The Lancet.

14. Wang Y, McKee M, Torbica A, Stuckler D. Systematic literature review on the spread of health-related misinformation on social media. Social Science \& Medicine. 2019:112552.

15. Kelvin DJ, Rubino S. Fear of the novel coronavirus. The Journal of Infection in Developing Countries. 2020;14(01):1-2.

16. Lai J, Ma S, Wang Y, Cai Z, Hu J, Wei N, et al. Factors associated with mental health outcomes among health care workers exposed to coronavirus disease 2019. JAMA network open. 2020;3(3):e203976-e.

17. Lima CKT, de Medeiros Carvalho PM, Lima IdAS, de Oliveira Nunes JVA, Saraiva JS, de Souza RI, et al. The emotional impact of Coronavirus 2019-nCoV (new Coronavirus disease). Psychiatry Research. 2020:112915.

18. Barbisch D, Koenig KL, Shih F-Y. Is there a case for quarantine? Perspectives from SARS to Ebola. Disaster medicine and public health preparedness. 2015;9(5):547-53.

19. Kang L, Ma S, Chen M, Yang J, Wang Y, Li R, et al. Impact on mental health and perceptions of psychological care among medical and nursing staff in Wuhan during the 2019 novel coronavirus disease outbreak: A cross-sectional study. Brain, behavior, and immunity. 2020. 
20. Asmundson GJ, Taylor S. Coronaphobia: Fear and the 2019-nCoV outbreak. Journal of anxiety disorders. 2020;70:102196.

21. Gerhold L. COVID-19: Risk perception and Coping strategies.

22. Pakpour A, Griffiths M. The fear of COVID-19 and its role in preventive behaviors. Journal of Concurrent Disorders.

23. Zarghami M. Psychiatric aspects of coronavirus (2019-nCoV) infection. Iran J Psychiatry Behav Sci. 2020;14(1):2019-21.

24. Zegarra-Valdivia J, Vilca BNC, Guerrero Knowledge, perception and attitudes in Regard to COVID-19 Pandemic in Peruvian Population. 2020.

25. Kang L, Li Y, Hu S, Chen M, Yang C, Yang BX, et al. The mental health of medical workers in Wuhan, China dealing with the 2019 novel coronavirus. The Lancet Psychiatry. 2020;7(3):e14.

26. Bo H-X, Li W, Yang Y, Wang Y, Zhang Q, Cheung T, et al. Posttraumatic stress symptoms and attitude toward crisis mental health services among clinically stable patients with COVID-19 in China.

Psychological medicine. 2020:1-2.

27. Urooj U, Ansari A, Siraj A, Khan S, Tariq H. Expectations, Fears and Perceptions of doctors during Covid19 Pakistan Journal of Medical Sciences. 2020;36(COVID19- S4).

28. Alwani SS, Majeed MM, Hirwani MZ, Rauf S, Saad SM, Shah SH, et Evaluation of Knowledge, Practices, Attitude and Anxiety of Pakistans Nurses towards COVID-19 during the Current Outbreak in Pakistan. medRxiv. 2020.

29. Faridah Amin SS, Rabeeya Saeed et COVID-19 Pandemic- Knowledge, Perception, Anxiety and Depression Among Frontline Doctors of Pakistan. Research Square. 2020.

30. Ahmed MA, Jouhar R, Ahmed N, Adnan S, Aftab M, Zafar MS, et Fear and practice modifications among dentists to combat Novel Coronavirus Disease (COVID-19) outbreak. International journal of environmental research public health. 2020;17(8):2821.

31. Ahmed N, Shakoor M, Vohra F, Abduljabbar T, Mariam Q, Rehman Knowledge, Awareness and Practice of Health care Professionals amid SARS-CoV-2, Corona Virus Disease Outbreak. Pakistan Journal of Medical Sciences. 2020;36(COVID19-S4).

32. Transforming and scaling up health professionals' education and training. World Health Organization Guidelines. 2013.

33. Ahorsu DK, Lin C-Y, Imani V, Saffari M, Griffiths MD, Pakpour A. The fear of COVID-19 scale: development and initial validation. International journal of mental health addiction. 2020.

34. Adelson JL, McCoach DBJE. Measuring the mathematical attitudes of elementary students: The effects of a 4-point or 5-point Likert-type scale. Educational Psychological measurement. 2010;70(5):796-807.

35. Gliem JA, Gliem RR, Calculating, interpreting, and reporting Cronbach's alpha reliability coefficient for Likert-type scales2003: Midwest Research-to-Practice Conference in Adult, Continuing, and Community

36. Liu Q, Luo D, Haase JE, Guo Q, Wang XQ, Liu S, et The experiences of health-care providers during the COVID-19 crisis in China: a qualitative study. The Lancet Global Health. 2020. 
37. Rajkumar RP. COVID-19 and mental health: A review of the existing literature. Asian journal of psychiatry. 2020:102066.

38. Li S, Li L, Zhu X, Wang Y, Zhang J, Zhao L, et al. Comparison of characteristics of anxiety sensitivity across career stages and its relationship with nursing stress among female nurses in Hunan, China. BMJ open. 2016;6(5):e010829.

39. Amin F, Sharif S, Saeed R, Durrani N, Jilani D. COVID-19 Pandemic-Knowledge, Perception, Anxiety and Depression Among Frontline Doctors of Pakistan.

40. Amber Ather B, Nikita B. Coronavirus Disease 19 (COVID-19): Implications for Clinical Dental Care. Journal of Endodontics. 2020;46(5).

41. Uddin KB. Work from home: New routines, unexplored territories, and unexpected shortcomings: Geo.tv; 2020 [updated 18th April 2020. Work from home was not a common concept for Pakistanis, but now everyone has moved towards this trend]. Available from: https://www.geo.tv/latest/283327-work-fromhome-new-routines-unexplored-territories-and- unexpected-shortcomings.

42. Shah Coronavirus kills 17 healthcare workers in Pakistan. The News. 2020 30th May 2020.

43. Chen W, Huang Y. To Protect Health Care Workers Better, To Save More Lives With COVID-19. Anesthesia Analgesia. 2020.

44. ERSOY A. The frontline of the COVID-19 pandemic: Healthcare workers. Turkish Journal of Internal Medicine.2(2):31-2.

45. Taghizadeh F, Hassannia L, Moosazadeh M, Zarghami M, Taghizadeh H, Dooki AF, et al. Anxiety and Depression in Health Workers and General Population During COVID-19 Epidemic in IRAN: A Web-Based Cross-Sectional Study. medRxiv.

46. Xiao H, Zhang Y, Kong D, Li S, Yang The effects of social support on sleep quality of medical staff treating patients with coronavirus disease 2019 (COVID-19) in January and February 2020 in China. Medical science monitor: international medical journal of experimental clinical research. 2020;26:e923549-1.

47. Mohindra R, Suri V, Bhalla A, Singh S. Issues relevant to mental health promotion in frontline health care providers managing quarantined/isolated COVID19 patients. Asian Journal of Psychiatry. 2020;51:102084.

48. Cai H, Tu B, Ma J, Chen L, Fu L, Jiang Y, et al. Psychological Impact and Coping Strategies of Frontline Medical Staff in Hunan Between January and March 2020 During the Outbreak of Coronavirus Disease 2019 (COVID-19) in Hubei, China. Medical science monitor: international medical journal of experimental clinical research. 2020;26:e924171-1.

49. Mak IWC, Chu CM, Pan PC, Yiu MGC, Chan VL. Long-term psychiatric morbidities among SARS survivors. General hospital psychiatry. 2009;31(4):318-26.

50. Kurji Z, Premani ZS, Mithani Analysis of the health care system of Pakistan: lessons learnt and way forward. Ayub Med Coll Abbottabad. 2016;28(3):601.

51. Shanafelt T, Ripp J, Trockel M. Understanding and addressing sources of anxiety among health care professionals during the COVID-19 pandemic. Jama. 
52. Chen $\mathrm{K}-\mathrm{Y}$, Yang C-M, Lien $\mathrm{C}-\mathrm{H}$, Chiou H-Y, Lin M-R, Chang H-R, et Burnout, job satisfaction, and medical malpractice among physicians. International journal of medical sciences. 2013;10(11):1471.

53. Adams JG, Walls RM. Supporting the health care workforce during the COVID-19 global epidemic. Jama. 2020;323(15):1439-40.

54. Chen Q, Liang M, Li Y, Guo J, Fei D, Wang L, et al. Mental health care for medical staff in China during the COVID-19 outbreak. The Lancet Psychiatry. 2020;7(4):e15-e6.

55. Cohen IG, Crespo AM, White DB. Potential legal liability for withdrawing or withholding ventilators during COVID-19: assessing the risks and identifying needed Jama. 2020;323(19):1901-2.

56. Lee SM, Kang WS, Cho A-R, Kim T, Park Psychological impact of the 2015 MERS outbreak on hospital workers and quarantined hemodialysis patients. Comprehensive psychiatry. 2018;87:123-7.

57. Maunder R, Hunter J, Vincent L, Bennett J, Peladeau N, Leszcz M, et The immediate psychological and occupational impact of the 2003 SARS outbreak in a teaching hospital. Cmaj. 2003;168(10):1245-51.

58. Rana W, Mukhtar S, Mukhtar S. Mental health of medical workers in Pakistan during the pandemic COVID-19 outbreak. Asian journal of psychiatry. 2020;51:102080.

59. Banerjee D. The COVID-19 outbreak: Crucial role the psychiatrists can play. Asian journal of psychiatry. 2020;50:102014.

60. Saqlain M, Munir MM, Rehman SU, Gulzar A, Naz S, Ahmed Z, et al. Knowledge, attitude, practice and perceived barriers among healthcare professionals regarding COVID-19: A Cross-sectional survey from Pakistan. Journal of Hospital Infection.

\section{Tables}

Table 1. Cronbach alpha and item-test correlation

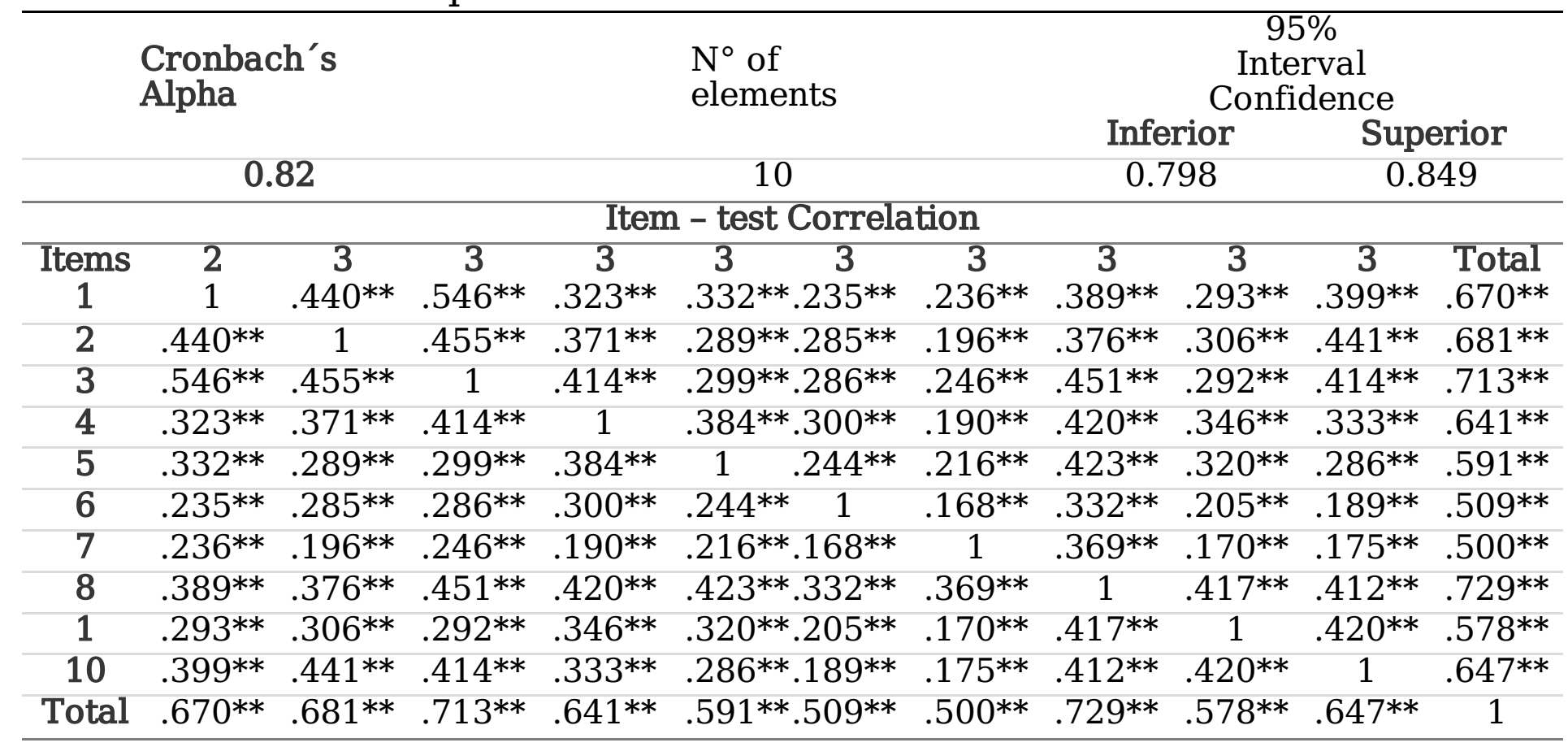


Table 2. Sociodemographic characteristics of the sample

Gender

\% Male $(n=141) \quad \%$ Female $(n=263) \quad \%$ All $(n=404) \quad X 2 \quad P$ value Age group

\begin{tabular}{|c|c|c|c|c|c|}
\hline $18-30$ years & $13.8 \%(56)$ & $44.5 \%(180)$ & $58.4 \%(236)$ & & \\
\hline $31-40$ years & $11.8 \%(48)$ & $15.8 \%(64)$ & $27.7 \%(112)$ & & \\
\hline 41-50 years & $2.9 \%(12)$ & $2.7 \%(11)$ & $5.6 \%(23)$ & 46.356 & $<0.001 * *$ \\
\hline $51-60$ years & $2.2 \%(9)$ & $1.4 \%(6)$ & $3.7 \%(15)$ & & \\
\hline$>61$ years & $3.9 \%(16)$ & $0.4 \%(2)$ & $4.4 \%(18)$ & & \\
\hline \multicolumn{6}{|l|}{ Profession } \\
\hline Dentist & $10 \%(44)$ & $30 \%(122)$ & $41.1 \%(166)$ & & \\
\hline Medical Doctor & $14 \%(57)$ & $16.5 \%(67)$ & $30.7 \%(124)$ & 12.017 & 0.007 \\
\hline Pharmacist & $3 \%(14)$ & $5.6 \%(23)$ & $9.2(37)$ & & \\
\hline Nurse & $6 \%(26)$ & $12.6 \%(51)$ & $19.1(77)$ & & \\
\hline
\end{tabular}

Does anyone in your family infected with covid19? -

\begin{tabular}{cccccc} 
Yes & 36.2 & 34.2 & 34.9 & 0.743 & $0.388 \mathrm{a}$ \\
No & 63.8 & 65.8 & 65.1 & & \\
\hline Anxiety Levels & & & & & \\
\hline No anxiety & $\%(0)$ & $0.2 \%(1)$ & $0.2 \%(1)$ & & \\
Mild anxiety & $1.2 \%(7)$ & $0.7 \%(3)$ & $2.4 \%(10)$ & & \\
\hline moderate anxiety & $5.4 \%(22)$ & $12.1 \%(49)$ & $17.5 \%(71)$ & 11.635 & $0.020^{*}$ \\
\hline High anxiety & $23.7 \%(96)$ & $38.8 \%(157)$ & $62.6 \%(253)$ & & \\
\hline Severe anxiety & $3.9 \%(16)$ & $13.1 \%(53)$ & $17 \%(69)$ & & \\
\hline
\end{tabular}

$X 2$ : Chi-square test, a: Fisher Test 
Table 3. Percentages of responses between Health care professionals

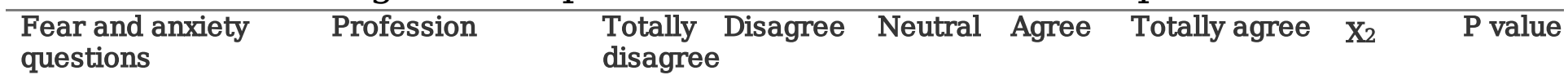

regarding

COVID19

\begin{tabular}{|c|c|c|c|c|c|c|c|c|}
\hline \multirow{3}{*}{$\begin{array}{c}\text { 1- It makes me } \\
\text { uncomfortable to } \\
\text { think about } \\
\text { coronavirus-19. }\end{array}$} & Dentist & $1.80 \%$ & $9.60 \%$ & $40.10 \%$ & $44.30 \%$ & $4.20 \%$ & \multirow[b]{2}{*}{22.265} & \multirow[b]{2}{*}{0.035} \\
\hline & Medical Doctor & $0.00 \%$ & $0.80 \%$ & $9.70 \%$ & $65.30 \%$ & $24.20 \%$ & & \\
\hline & Pharmacist & $2.70 \%$ & $2.70 \%$ & $0.00 \%$ & $54.10 \%$ & $40.50 \%$ & & \\
\hline \multirow{5}{*}{$\begin{array}{l}\text { 2.- I am afraid of } \\
\text { losing my life } \\
\text { because of } \\
\text { coronavirus-19 }\end{array}$} & Nurse & $0.00 \%$ & $0.00 \%$ & $1.30 \%$ & $27.60 \%$ & $71.10 \%$ & & \\
\hline & Dentist & $9.00 \%$ & $34.10 \%$ & $38.90 \%$ & $15.60 \%$ & $2.40 \%$ & & \\
\hline & Medical Doctor & $0.00 \%$ & $3.20 \%$ & $39.50 \%$ & $44.40 \%$ & $12.90 \%$ & 21.266 & 0.047 \\
\hline & Pharmacist & $0.00 \%$ & $10.80 \%$ & $18.90 \%$ & $40.50 \%$ & $29.70 \%$ & & \\
\hline & Nurse & $0.00 \%$ & $2.60 \%$ & $6.60 \%$ & $50.00 \%$ & $40.80 \%$ & & \\
\hline \multirow{4}{*}{$\begin{array}{l}\text { 3.- When watching } \\
\text { news and stories } \\
\text { about coronavirus- } \\
19 \text { on social media, } \\
\text { I become nervous } \\
\text { or anxious. }\end{array}$} & Dentist & $3.60 \%$ & $25.10 \%$ & $31.10 \%$ & $37.10 \%$ & $3.00 \%$ & & \\
\hline & Medical Doctor & $0.00 \%$ & $3.20 \%$ & $14.50 \%$ & $62.90 \%$ & $19.40 \%$ & 26.390 & 0.009 \\
\hline & Pharmacist & $0.00 \%$ & $0.00 \%$ & $5.40 \%$ & $64.90 \%$ & $29.70 \%$ & & \\
\hline & Nurse & $0.00 \%$ & $0.00 \%$ & $2.60 \%$ & $32.90 \%$ & $64.50 \%$ & & \\
\hline \multirow{4}{*}{$\begin{array}{l}\text { 4.- I'm afraid of the } \\
\text { depression and } \\
\text { anxiety the disease } \\
\text { has caused in the } \\
\text { society }\end{array}$} & Dentist & $1.20 \%$ & $12.00 \%$ & $23.40 \%$ & $53.90 \%$ & $9.60 \%$ & & \\
\hline & Medical Doctor & $0.00 \%$ & $0.00 \%$ & $5.60 \%$ & $66.10 \%$ & $28.20 \%$ & 18.393 & 0.104 \\
\hline & Pharmacist & $0.00 \%$ & $0.00 \%$ & $0.00 \%$ & $27.00 \%$ & $73.00 \%$ & & \\
\hline & Nurse & $0.00 \%$ & $1.30 \%$ & $0.00 \%$ & $26.30 \%$ & $72.40 \%$ & & \\
\hline \multirow{4}{*}{$\begin{array}{l}\text { 5.- The negative } \\
\text { impact of the } \\
\text { disease on the } \\
\text { current and future } \\
\text { economy stresses } \\
\text { me out }\end{array}$} & Dentist & $1.20 \%$ & $9.00 \%$ & $16.20 \%$ & $62.30 \%$ & $11.40 \%$ & & \\
\hline & Medical Doctor & $0.00 \%$ & $1.60 \%$ & $8.10 \%$ & $54.00 \%$ & $36.30 \%$ & 21.744 & 0.040 \\
\hline & Pharmacist & $0.00 \%$ & $0.00 \%$ & $8.10 \%$ & $32.40 \%$ & $59.50 \%$ & & \\
\hline & Nurse & $0.00 \%$ & $0.00 \%$ & $3.90 \%$ & $18.40 \%$ & $77.60 \%$ & & \\
\hline \multirow{4}{*}{$\begin{array}{l}\text { 6.- I fear disease } \\
\text { transmission to } \\
\text { others than being } \\
\text { affected by it } \\
\text { myself }\end{array}$} & Dentist & $1.80 \%$ & $6.00 \%$ & $24.60 \%$ & $47.90 \%$ & $19.80 \%$ & & \\
\hline & Medical Doctor & $0.00 \%$ & $3.20 \%$ & $5.60 \%$ & $62.90 \%$ & $28.20 \%$ & 5.346 & 0.945 \\
\hline & Pharmacist & $0.00 \%$ & $2.70 \%$ & $2.70 \%$ & $40.50 \%$ & $54.10 \%$ & & \\
\hline & Nurse & $0.00 \%$ & $0.00 \%$ & $3.90 \%$ & $22.40 \%$ & $73.70 \%$ & & \\
\hline \multirow{4}{*}{$\begin{array}{l}\text { 7.- I fear the } \\
\text { period of } \\
\text { quarantine } \\
\text { following COVID- } \\
19 \text { more than the } \\
\text { disease symptoms }\end{array}$} & Dentist & $5.40 \%$ & $29.90 \%$ & $24.00 \%$ & $37.10 \%$ & $3.60 \%$ & & \\
\hline & Medical Doctor & $2.40 \%$ & $17.70 \%$ & $19.40 \%$ & $46.00 \%$ & $14.50 \%$ & 21.381 & 0.045 \\
\hline & Pharmacist & $0.00 \%$ & $5.40 \%$ & $27.00 \%$ & $37.80 \%$ & $29.70 \%$ & & \\
\hline & Nurse & $0.00 \%$ & $1.30 \%$ & $18.40 \%$ & $35.50 \%$ & $44.70 \%$ & & \\
\hline \multirow{4}{*}{$\begin{array}{l}\text { 8.- The uncertainty } \\
\text { of when COVID-19 } \\
\text { will be eradicated } \\
\text { stresses me out }\end{array}$} & Dentist & $1.80 \%$ & $12.00 \%$ & $28.70 \%$ & $50.30 \%$ & $7.20 \%$ & & \\
\hline & Medical Doctor & $0.00 \%$ & $1.60 \%$ & $7.30 \%$ & $66.90 \%$ & $24.20 \%$ & 14.337 & 0.280 \\
\hline & Pharmacist & $0.00 \%$ & $0.00 \%$ & $0.00 \%$ & $27.00 \%$ & $73.00 \%$ & & \\
\hline & Nurse & $0.00 \%$ & $1.30 \%$ & $0.00 \%$ & $22.40 \%$ & $76.30 \%$ & & \\
\hline \multirow{4}{*}{$\begin{array}{c}\text { 9.- Lack of health } \\
\text { facilities in our } \\
\text { country stresses } \\
\text { me out }\end{array}$} & Dentist & $1.20 \%$ & $4.80 \%$ & $10.80 \%$ & $57.50 \%$ & $25.70 \%$ & & \\
\hline & Medical Doctor & $0.00 \%$ & $0.00 \%$ & $4.00 \%$ & $33.10 \%$ & $62.90 \%$ & 17.670 & 0.126 \\
\hline & Pharmacist & $0.00 \%$ & $0.00 \%$ & $0.00 \%$ & $18.90 \%$ & $81.10 \%$ & & \\
\hline & Nurse & $0.00 \%$ & $0.00 \%$ & $1.30 \%$ & $19.70 \%$ & $78.90 \%$ & & \\
\hline \multirow{3}{*}{$\begin{array}{l}\text { 10.- Transmission } \\
\text { of disease despite } \\
\text { taking all } \\
\text { precautionary } \\
\text { measures during }\end{array}$} & Dentist & $3.00 \%$ & $10.20 \%$ & $24.60 \%$ & $53.30 \%$ & $9.00 \%$ & & \\
\hline & Medical Doctor & $0.80 \%$ & $0.80 \%$ & $12.10 \%$ & $55.60 \%$ & $30.60 \%$ & 15.818 & 0.200 \\
\hline & Pharmacist & $0.00 \%$ & $0.00 \%$ & $2.70 \%$ & $16.20 \%$ & $81.10 \%$ & & \\
\hline
\end{tabular}




\section{$X_{2}$ : Chi-square}

\begin{tabular}{cccc}
\hline \multicolumn{4}{c}{ Table 4. Multi-linear regression of fear and anxiety total } \\
score and sociodemographic variables \\
\hline R squared & SEE & $\mathrm{F}$ & $\mathrm{p}$ value \\
0.616 & 3.47049 & 159.755 & $<0.001^{* *}$ \\
\hline \multicolumn{4}{c}{ Coefficients } \\
Variables & $\beta$ & SEE & p value \\
\hline (Constant) & 32.962 & 0.84 & $<0.001^{* *}$ \\
Age & -0.173 & 0.176 & 0.326 \\
Gender & 0.232 & 0.386 & 0.547 \\
\hline Profession & 2.813 & 0.113 & $<0.001^{* *}$ \\
\hline Item 1 & -0.479 & 0.363 & 0.188 \\
\hline
\end{tabular}

$\mathrm{SEE}=$ Standard error of the estimation,

\section{Figures}

Figure 1 Mean anxiety scores of Healthcare Professionals.

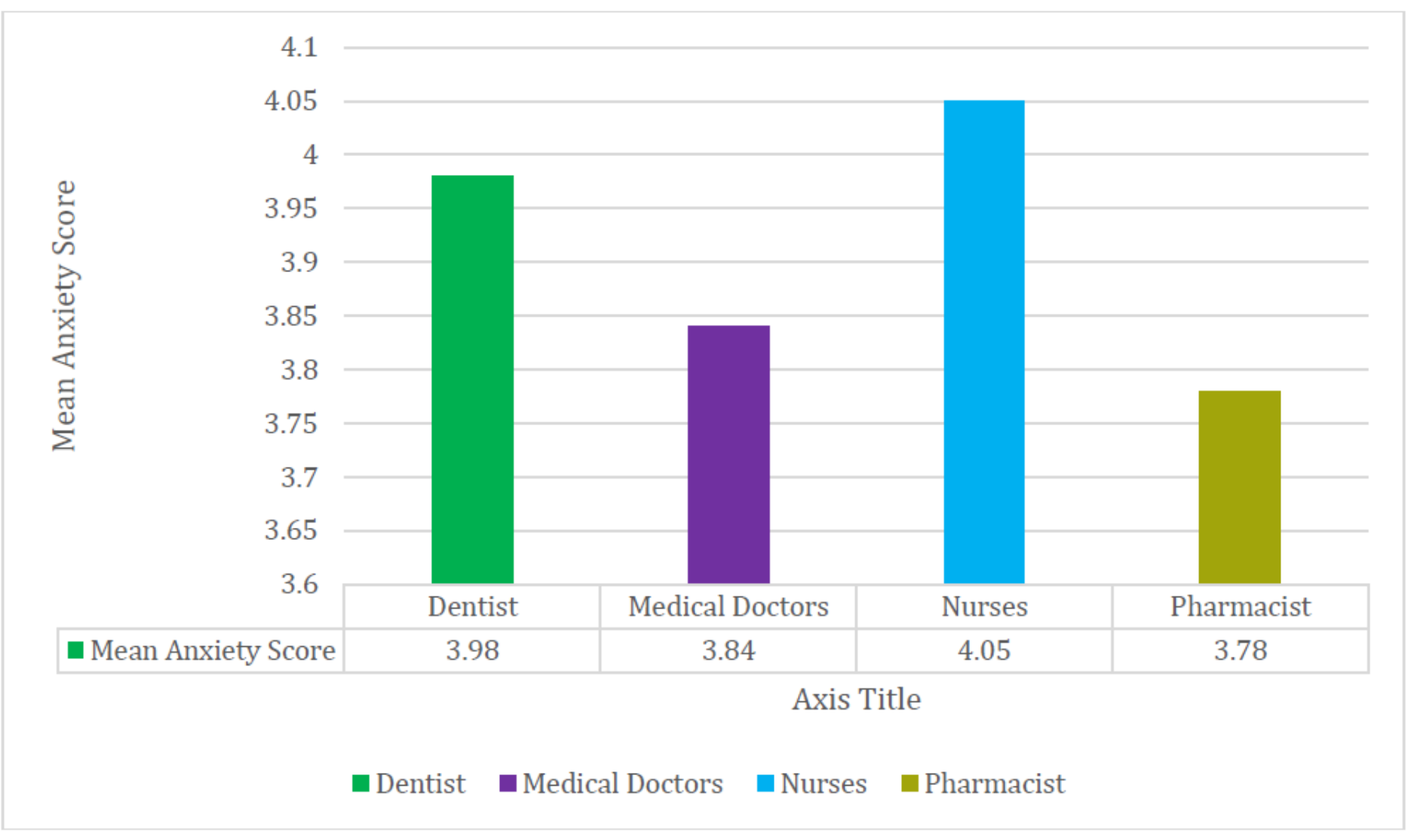


Figure 1

Mean anxiety scores of Healthcare Professionals.

Figure 2. The contrast of total score by sociodemographic characteristics. A. Gender, B. Age, C., Gender and Question (any of your family have COVID-19?), D. Profession.
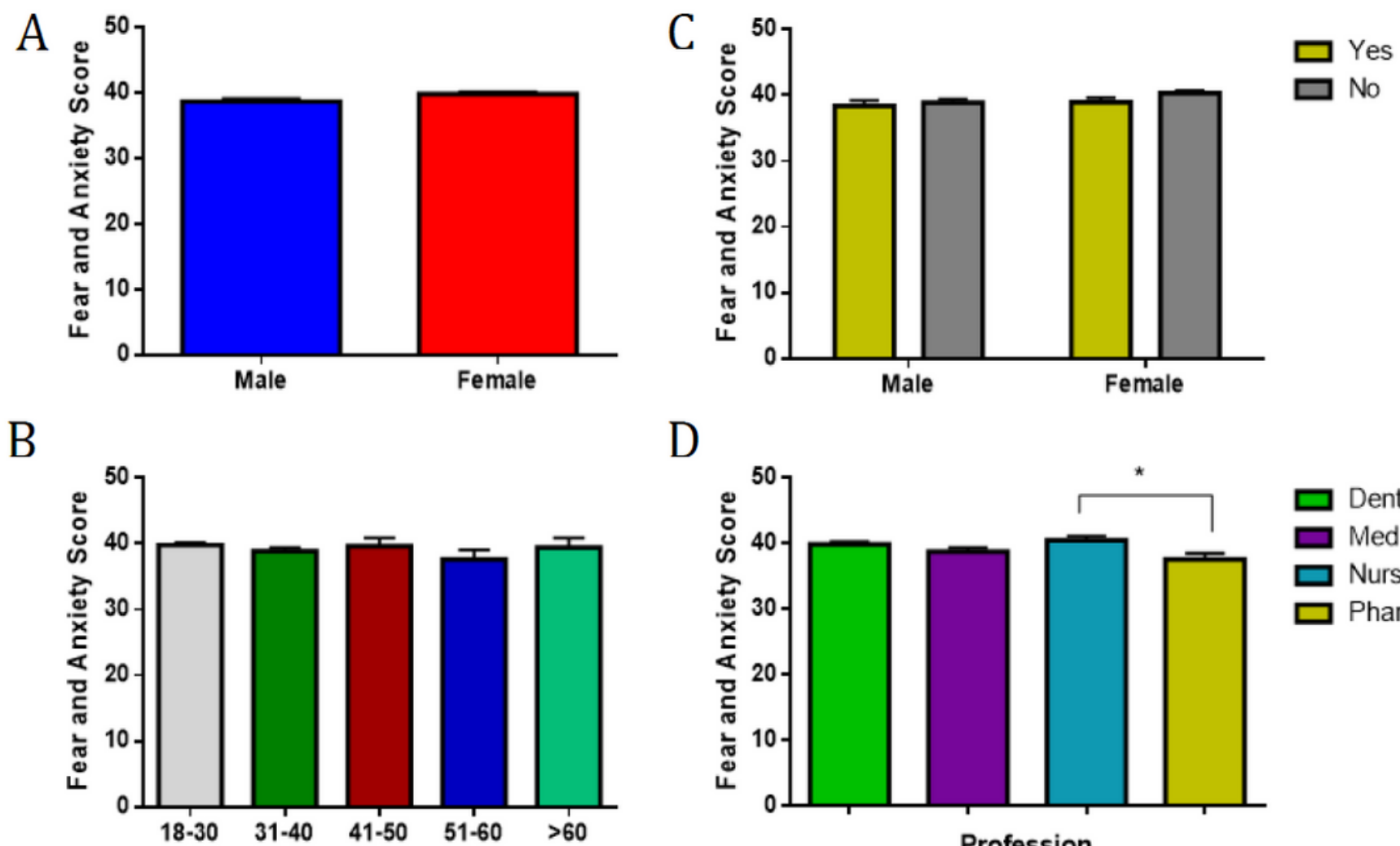

$\mathrm{D}$

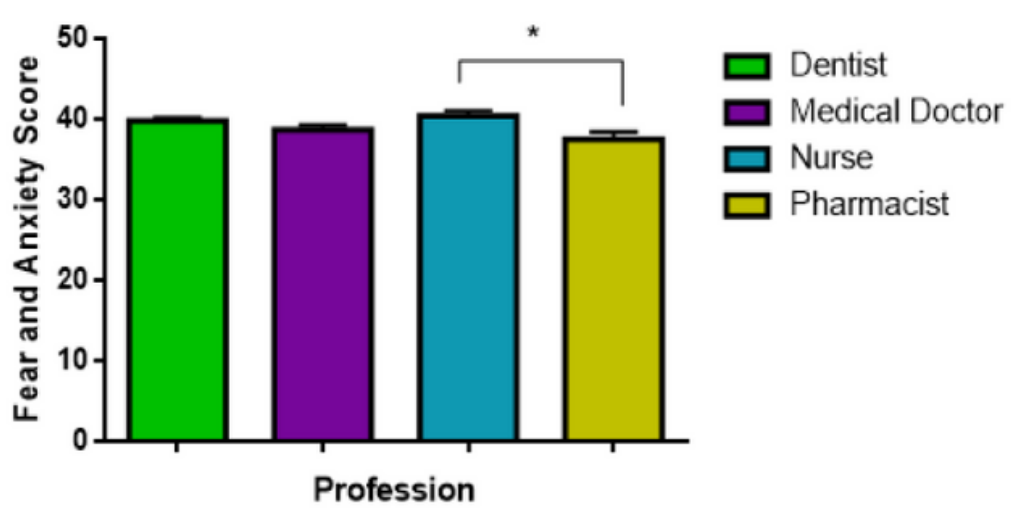

Figure 2

The contrast of total score by sociodemographic characteristics. A. Gender, B. Age, C., Gender and Question (any of your family have COVID-19?), D. Profession. 